\title{
Anatomical Pathology Laboratory Activity in Meknes, Morocco
}

\author{
Hajar El Hilali ${ }^{*}$, Fatiha El Hilali ${ }^{1}$, Bakary Traore ${ }^{2}$, Fatiha Laziri ${ }^{1}$ \\ ${ }^{1}$ Department of Biology, Moulay Ismail University of Meknes, Meknes, Morocco \\ ${ }^{2}$ Faculty of Medicine and Pharmacy, Sidi Mohamed Benabdellah University, Fez, Morocco \\ Email: *elhajar83@gmail.com
}

How to cite this paper: El Hilali, H., El Hilali, F., Traore, B. and Laziri, F. (2019) Anatomical Pathology Laboratory Activity in Meknes, Morocco. Open Journal of Pathology, 9, 50-57. https://doi.org/10.4236/ojpathology.2019.9 $\underline{3006}$

Received: March 10, 2019

Accepted: July 23, 2019

Published: July 26, 2019

Copyright $\odot 2019$ by author(s) and Scientific Research Publishing Inc. This work is licensed under the Creative Commons Attribution International License (CC BY 4.0).

http://creativecommons.org/licenses/by/4.0/

\begin{abstract}
Cancer continues to be a major health problem in the world. During 2018, there were 9.6 million deaths and 18.1 million new cases registered across the globe. It is estimated that one in 5 men and one in 6 women will develop cancer during their lifetime. This disease kills one in 8 men and one in 11 women. Developing countries have seen an increase in cancer occurrence and change in type of cancers due to change in social and economic conditions. The objective of this research was to further evaluate 1659 specimens for anatomical pathology testing. The data was collected from the records of the pathological anatomy laboratory at the Mohamed V Hospital in Meknes, Morocco. It is one-year study period (January-December 2013). Results of the anatomy pathology exam showed cancer positive for $9.6 \%$ of specimens; inconclusive for $1 \%$; and negative for $66.2 \%$. For all specimens, the most analyzed organs are breast with $29.7 \%$; skin with $21.3 \%$; cervical with $2.6 \%$. For cancer patients, the most affected organs are skin (21.3\%) and breast (29.7\%). For cancer patients, Neoplasm is present in $9.3 \%$ of patients. Patients with metastatic cancer represent $0.3 \%$. Patients with non-neoplastic lesions represent $66.2 \% .1 \%$ of patients represent uncertain results. Additional immunohistochemistry research is needed before conclusive recommendations are made.
\end{abstract}

\section{Keywords}

Cancer, Breast Cancer, Morocco, Health System, Anatomical Pathology Testing

\section{Introduction}

Cancer is a leading cause of death worldwide, accounting for an estimated 9.6 million deaths in 2018 (WHO, 2018). Cancer is a public health burden in terms of morbidity and mortality in both developing and industrialized countries. However, approximately $70 \%$ of deaths from cancer occur in low- and mid- 
dle-income countries (WHO, 2018). The most common cancers are: Lung (2.09 million cases), Breast (2.09 million cases), Colorectal (1.80 million cases), Prostate (1.28 million cases), Skin cancer (non-melanoma) (1.04 million cases) and Stomach (1.03 million cases). In Morocco the most common cancer in women is breast followed by cervical cancer. In men lung cancer followed by prostate cancer occurs most often [1]. According to the Cancer Registry of the Grand Casablanca Region (RCRC) 2004, the estimate of new cases of cancer currently in Morocco was 30,500/year [2]. The most common causes of cancer death are cancers of: Lung (1.76 million deaths), Colorectal (862,000 deaths), Stomach (783,000 deaths), Liver (782,000 deaths) and Breast (627,000 deaths). It is now concluding that many familial cancers emerge, not exclusively from genetic makeup, but from the interaction between common gene variations and lifestyle and environmental risk Factors [3]. The incidence of cancer has increased considerably in recent decades, this increase is related to various risk factors including behavioral (Tobacco, Alcohol Use, Diet, Overweight and Obesity, and Physical Inactivity), environmental (industrialization, food contaminants, infections, urbanization, pollution, ionizing radiation from natural, industrial, and medical sources ultraviolet radiation, etc.) and genetics (genetic predisposition for certain cancers, genetic mutations and instabilities, hormonal and reproductive factors, immunosuppression). Around one third of deaths from cancer are due to the 5 leading behavioral and dietary risks: high body mass index, low fruit and vegetable intake, lack of physical activity, tobacco use, and alcohol use (WHO, 2018) [4] [5].

Nevertheless, the enormous disparities in wealth between developing and developed countries may also be relevant in the types, frequency, and outcomes of cancer that occur in these settings (NIH, 2018). According to the latest report by WHO, the Moroccan Cancer Mortality Profile shows: total deaths = 206,000; 12,500 Deaths for men and 10,400 Deaths of women (World Health Organization-Cancer Country Profiles, 2014). Reduction and control cancer can be conceived by implementing evidence-based strategies for cancer prevention, early detection of cancer and management of patients with cancer [6]. Many cancers have a high chance of cure if detected early and treated adequately. For this very reason, in 2005 the Lalla Salma Foundation for the Prevention and Treatment of Cancer was created in Morocco by Princess Lalla Salma and its main objective was to install a national plan for the prevention and to fight against cancer in Morocco. Thusly, the Oncology Center of Meknes was born in June 2014. Further cervical cancer can be prevented also by vaccination of adolescent girls and young women, good hygiene and commencement of screening of women aged 25 to 35 years [7] [8].

Therefore, the objective of this research was to further investigate and evaluate 1659 specimens for anatomical pathology testing. The data was collected from the records of the pathological anatomy laboratory at the Mohamed V Hospital in Meknes, Morocco. It is one-year study period (January-December 2013). 


\section{Materials and Methods}

\subsection{Technical Study and Data Collection}

This was retrospective study based on the primary data collected through patient's recorders from the pathological anatomy laboratory in the Mohamed V Hospital. It is one-year study period (January-December 2013). The data including age, gender, cancer sites, type of insurance and department.

\subsection{Statistical Analysis}

Statistical studies were performed using SPSS Statistical program package, version 20.0. T-test was applied to assess the extent of difference among parametric variables. Chi-square test was employed to judge the differences among non-parametric variables. Logistic regression was used as a power means to determine the significance and direction of association between transfusion and other variables.

\section{Results}

During the 1-year study period, 1659 specimens for anatomical pathology testing were received. From the 1659 specimens testing, the anatomy pathology exam was cancer positive for 9.6\%; inconclusive for $1 \%$; and negative for $66.2 \%$. For all specimens, there were $53.9 \%$ females and $23.2 \%$ men (Figure 1). Cancer patients were $69 \%$ females and $31 \%$ men. During the months of June, May, July and March, the laboratory has been experiencing the most important activity. There were respectively $9.6 \% ; 9.6 \%$; $9.5 \%$ and $9.2 \%$ (Figure 2). $18.4 \%$ of patients were holders of Social and Health Card (RAMED). 28.5\% of patients were holders of certificate of indigence. The patients who pay represent $40.6 \%$ (Figure 3). For all specimens, the most analyzed organs were respectively Breast with $29.7 \%$; Skin with $21.3 \%$ Cervical with $2.6 \%$ (Figure 4). For cancer patients, the most affected organs were respectively Skin (21.3\%) and Breast (29.7\%). For all specimens, Surgery Department specimens represent 26.6\%. Out-patient specimens represented $10.3 \%$. For cancer patients, specimens from surgery, external and gynecological obstetrics department represent respectively $74.1 \%, 9.7 \%$ and $7.7 \%$. For cancer patients, Neoplasm presented $9.3 \%$ of patients. Patients with metastatic cancer represented $0.3 \%$. Patients with non-neoplastic lesions represented $66.2 \% .1 \%$ of patients represented uncertain results and additional immunohistochemistry

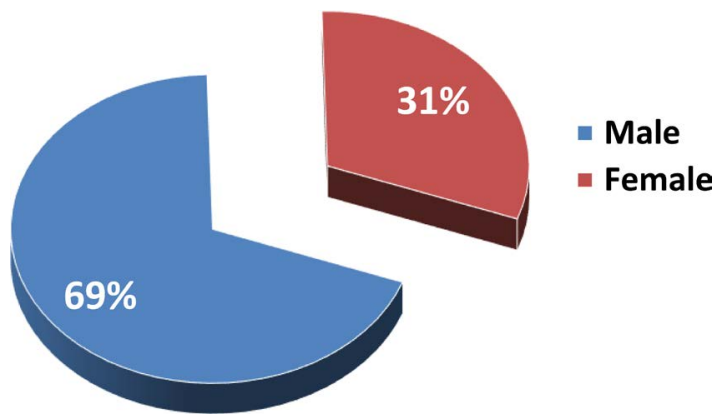

Figure 1. Distribution of admitted patients by gender. 


\section{H. EL Hilali et al.}

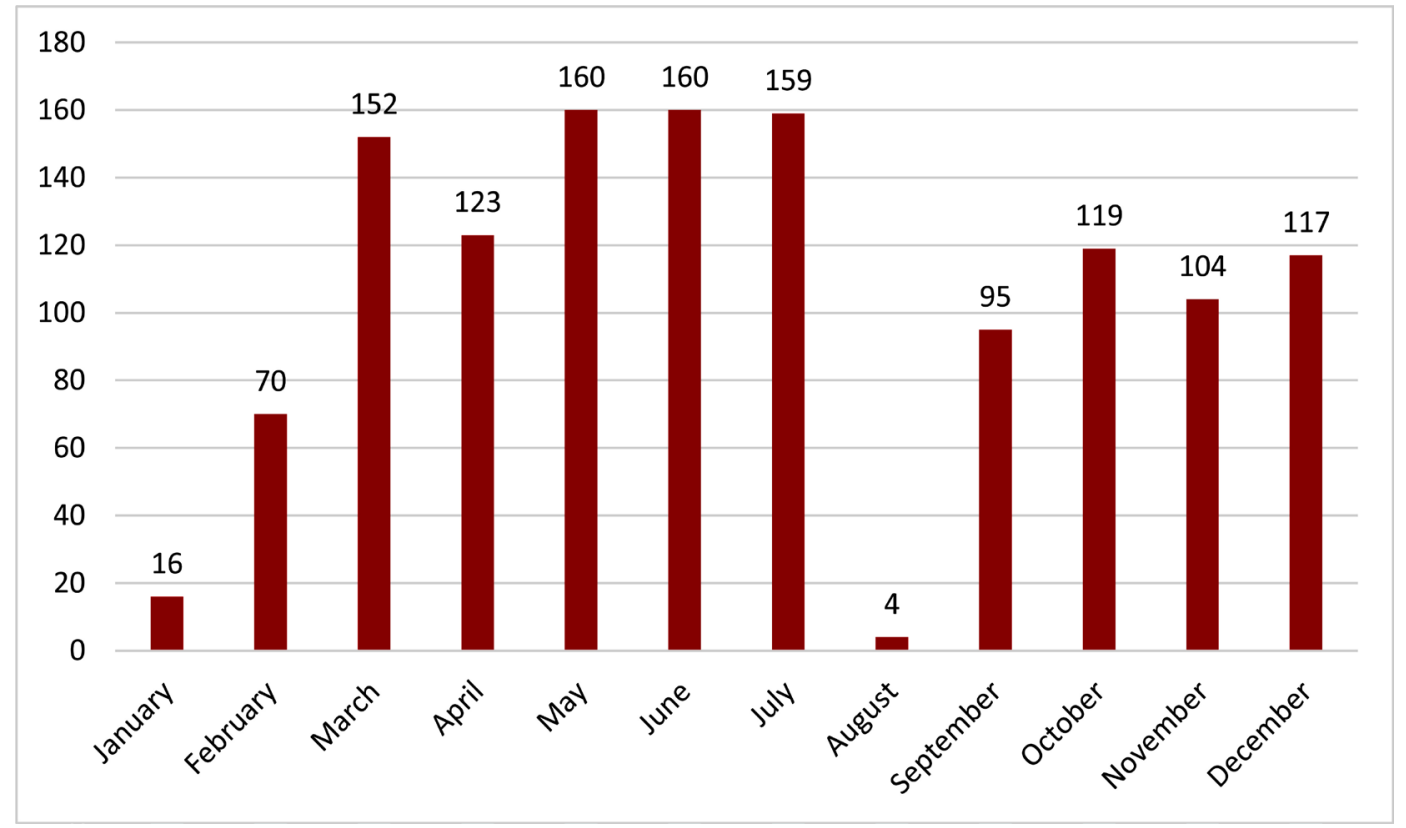

Figure 2. Distribution of admitted patients by month.

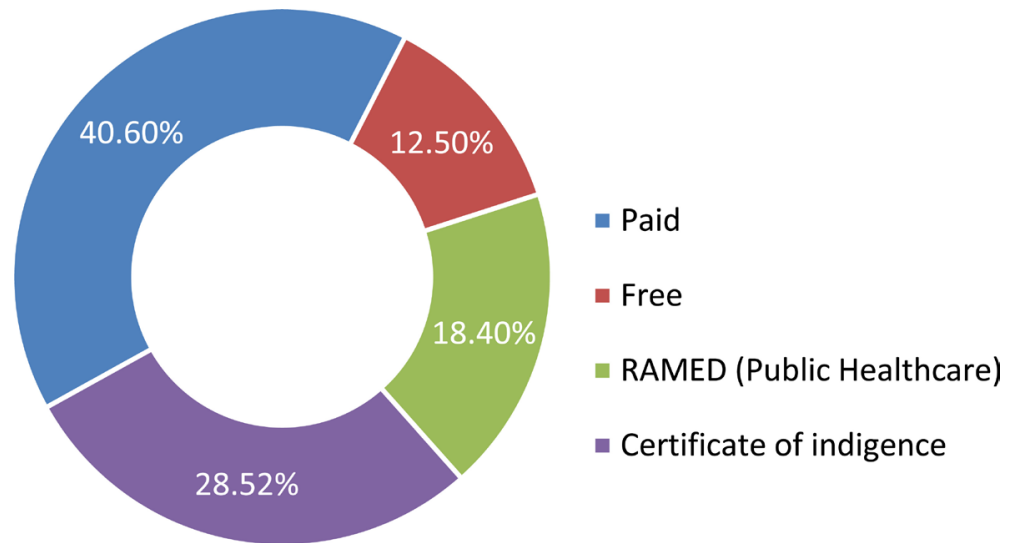

Figure 3. Distribution admitted patients by type of insurance.

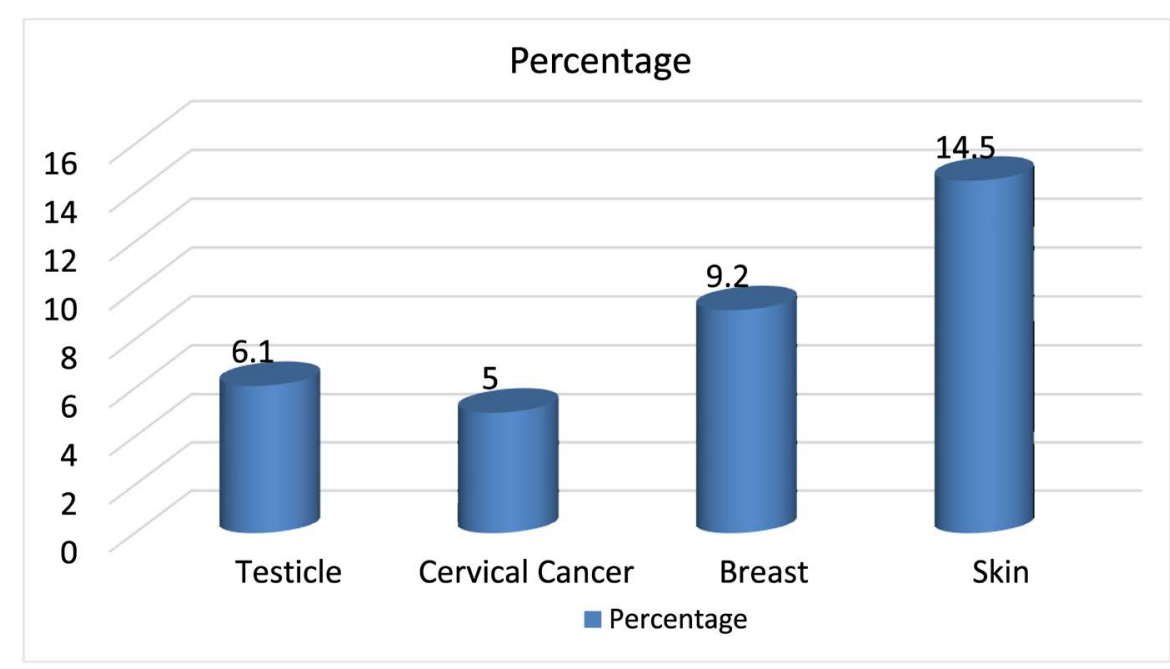

Figure 4. Distribution of admitted patients by affected organ. 
studies are needed (Figure 5). For all specimens, the average age was 44 year \pm 18.16 (range 2 - 97). For cancer patients, the average age was 54.44 years and $69 \%$ of patients are female (Figure 6). There was a significant association between organ and sex, the most female cancer are breast and cervical cancer, for men prostate and bronchus and lung. A highly significant relation between organ and age group, and women between 40 and 49 years old were the most affected by cervical and breast cancer, while the most affected men by bronchus and lung was between 60 and 69 years old. The men affected by prostate cancer were over than 70 years.

\section{Discussion}

Our study is the first conducted in Northern Central Morocco that analyzed cancer incidence based on specimens received by the laboratory of pathological anatomy. The most common cancers in women are breast and cervix cancers and the most common cancers in men are lungs followed by prostate. The results of the study are fairly consistent, agreeing with previous research [9] [10] [11]. These findings coincided with other national and international studies reported by the Grand Casablanca Register and WHO [2] [12]. The gender difference in

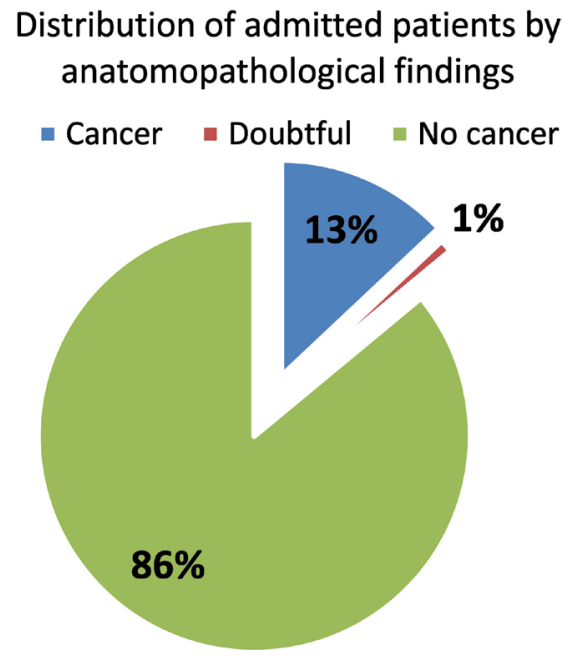

Figure 5. Distribution of admitted patients by anatomopathological findings.

Patients with cancer

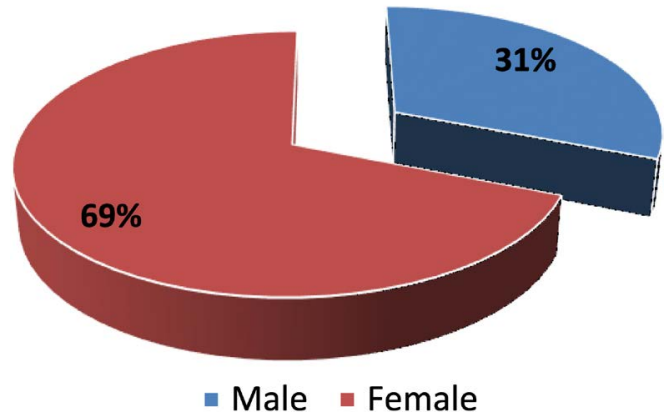

Figure 6. Distribution of patients with cancer by gender. 
cancer susceptibility is one of the subjects of considerable discussion in cancer epidemiology. According to our study, cancer incidence is higher in women than men; this finding coincides with other national and international studies [1] [9] [13] [14]. In a new study examined cancer knowledge, beliefs, and practice among faith-based Chinese in the USA versus Taiwan. Mean age was $44.31 ; 60 \%$ males [15]. Breast cancer is the most common cancer affecting women in Meknes region and prostate cancer is the most common cancer among men. Basal cell carcinoma (BCC) is equally common in both sexes. This unequivocally supports the findings from national and international papers. [9] [10] [16].

In our study, the average age of patients was 54.44 years. In the USA, age was a risk factors for breast cancer, the United States Preventative Services Task Force (USPSTF) recommends that women who are 50 to 74 years old to get a mammogram every two years [17]. In Chinese population in USA mean age was $44.31[15]$.

The most common cancer in women is breast cancer; while lung is the most common cancer for men; this finding is compared with many studies [18] [19]. Significant correlation was observed between sex and age in patient with cancer. This is consistent with British paper [20]. Women are affected by cancer at an earlier age (40 - 49 years) for breast and cervical cancer compared to men (60 69 years) this for bronchus, lungs and prostate cancers [11]. Similar to Mexico, in Venezuela and in Japan nearly one-half of women with breast carcinoma are younger than 50 years of age, and this resembles rates in many Latin American countries [11] [19] [21]. A Cameroonian study reported a pyramidal aspect of the frequency of these types of cancer with a peak between $40-49$ years [22]. In an Ivorian study, the same distribution was observed with a peak between 45 55 years [21]. Women with adequate negative screening at age $50-64 \mathrm{y}$ had one-sixth of the risk of cervical cancer at age $65-83$ y compared with women who were not screened. Stopping screening between ages 60 and $69 \mathrm{y}$ in women with adequate negative screening seems sensible, but further screening may be justifiable as life expectancy increases [23].

\section{Conflicts of Interest}

The authors declare no conflicts of interest regarding the publication of this paper.

\section{References}

[1] El Hilali, H., El Hilali, F., Samih, M. and Laziri, F. (2017) Cancer Incidence in Northern Central Moroccan Patients. Journal of Multidisciplinary Social Research, 4, 403-409.

[2] Association Lalla Salma de lutte contre le Cancer (2012) Registre des cancers de la région du Grand Casablanca.

[3] American Cancer Society (2015) Cancer Facts \& Figures American Cancer Society, Inc., Atlanta, GA.

https://www.cancer.org/research/cancer-facts-statistics/all-cancer-facts-figures/canc 
er-facts-figures-2015.html

[4] Hecht, S.S. (2012) Lung Carcinogenesis by Tobacco Smoke. International Journal of Cancer, 131, 2724-2732. https://doi.org/10.1002/ijc.27816

[5] $\mathrm{Mu}, \mathrm{L}$. and Mukamal, K.J. (2016) Alcohol Consumption and Rates of Cancer Screening: Is Cancer Risk Overestimated? Cancer Causes \& Control, 27, 281-289. https://doi.org/10.1007/s10552-015-0692-3

[6] Cialdella-Kam, L., Sabado, P., Bernstein, L., Bispeck, K., Hawk, E., Krawiec, V., O'Donnell, J.F. and Silverman, S. (2012) Implementing Cancer Prevention into Clinical Practice. Journal of Cancer Education, 27, 136-149.

https://doi.org/10.1007/s13187-012-0331-6

[7] Ngan, H.Y.S., Garland S.M., Bhatla, N., Pagliusi, S.R., Chan, K.K.L., Cheung, A.N.Y., Chu, T.Y., Domingo, E.J., Qiao, Y.L., Park, J.S., Tay, E.H. and Supakarapongku, W. (2011) Asia Oceania Guidelines for the Implementation of Programs for Cervical Cancer Prevention and Control. Journal of Cancer Epidemiology, 2011, Article ID: 794861. https://doi.org/10.1155/2011/794861

[8] Kim, H.W. and Kim, D.H. (2015) Awareness of Cervical Cancer Prevention among Mothers of Adolescent Daughters in Korea: Qualitative Research. BMJ Open, 5, e006915. https://doi.org/10.1136/bmjopen-2014-006915

[9] Bouchbika, Z., Haddad, H., Benchakroun, N., Eddakaoui, H., Kotbi, S., Megrini, A., Bourezgui, H., Sahraoui, S., Corbex, M., Harif, M. and Benider, A. (2013) Cancer Incidence in Morocco: Report from Casablanca Registry 2005-2007. The Pan African Medical Journal, 16, 31. https://doi.org/10.11604/pamj.2013.16.31.2791

[10] Registre Canadien du Cancer (2015) Réseau canadien des Centres de données de recherche. https://crdcn.org/fr/datasets/ccr-canadian-cancer-registry

[11] Guerrero, A.M., Genuino, A.J., Santillan, M., Praditsitthikorn, N., Chantarastapornchit, V., Teerawattananon, Y., Alejandria, M. and Toral, J.A. (2015) A Cost-Utility Analysis of Cervical Cancer Screening and Human Papillomavirus Vaccination in the Philippines. BMC Public Health, 15, 730. https://doi.org/10.1186/s12889-015-2046-1

[12] Stewart, B.W. and Wild, C.P. (2014) World Cancer Report 2014. World Health Organization. http://www.who.int/

[13] Institute National du Cancer (INCa) (2014) Les cancers en France. Institut national du Cancer, France.

[14] Galceran, J., Ameijide, A., Carulla, M., Mateos, A., Quirós, J.R., Rojas, D., Alemán, A., Torrella, A., Chico, M., Vicente, M., Díaz, J.M., Larrañaga, N., Marcos-Gragera, R., Sánchez, M.J., Perucha, J., Franch, P., Navarro, C., Ardanaz, E., Bigorra, J., Rodrigo, P. and Bonet, R.P. (2017) Cancer Incidence in Spain, 2015. Clinical and Translational Oncology, 19, 799-825. https://doi.org/10.1007/s12094-016-1607-9

[15] Hou, S.I. and Cao, X. (2019) A Cross-Sectional Study of Cancer Knowledge and Beliefs among Faith-Based Chinese in the USA versus Taiwan. Journal of Preventive Medicine \& Public Health, 52, 60-65. https://doi.org/10.3961/jpmph.17.051

[16] Organisation Mondiale de la Santé (2013) Dernières statistiques mondiales sur le cancer en augmentation à 14,1 millions de nouveaux cas en 2012: L'augmentation marquée du cancer du sein demande des réponses. Centre Internationale des Recherche sur le Cancer.

[17] Wellings, E., Vassiliades, L. and Abdalla, R. (2016) Breast Cancer Screening for High-Risk Patients of Different Ages and Risk-Which Modality Is Most Effective? Cureus, 8, e945. https://doi.org/10.7759/cureus.945 
[18] Escrich, E., Solanas, M. and Moral, R. (2014) Olive Oil and Other Dietary Lipids in Breast Cancer. In: Zappia, V., Panico, S., Russo, G., Budillon, A. and Della Ragione, F., Eds., Advances in Nutrition and Cancer. Cancer Treatment and Research, Springer, Berlin, Heidelberg, 289-309.

https://doi.org/10.1007/978-3-642-38007-5 17

[19] American Cancer Society (2017) Breast Cancer Facts \& Figures 2017-2018. American Cancer Society, Inc., Atlanta, GA.

[20] Maddams, J., Brewster, D., Gavin, A., Steward, J., Elliott, J., Utley, M. and Møller, H. (2009) Cancer Prevalence in the United Kingdom: Estimates for 2008. British Journal of Cancer, 101, 541-547. https://doi.org/10.1038/sj.bjc.6605148

[21] N’Dah, K.J., Doukoure, B., Troh, E., Aman, N.A., Koffi, K.E., Kouamé, A.D., Effi, A.B., D’Horpock, A.F. and Diomande, M.I.J. (2014) Epidemiological and Histological Aspects of Women Genital Cancers in Côte d'Ivoire. Open Journal of Obstetrics and Gynecology, 4, 516-523. https://doi.org/10.4236/ojog.2014.49073

[22] Engbang, J.P.N., Koh, V.M., Tchente, C.N. and Fewou, A. (2015) Histo-Epidemiological Aspects of Genital Cancers in Women in the Littoral Region, Cameroon. The Pan African Medical Journal, 21, 116.

[23] Castañón, A., Landy, R., Cuzick, J. and Sasieni, P. (2014) Cervical Screening at Age 50 - 64 Years and the Risk of Cervical Cancer at Age 65 Years and Older: Population Based Case Control Study. PLoS Medicine, 11, e1001585.

https://doi.org/10.1371/journal.pmed.1001585

https://www.ncbi.nlm.nih.gov/pubmed?linkname=pubmed pubmed\&from uid=23 $\underline{820257}$ 